\title{
Guidelines
}

\section{Adult Pulmonary Intensive and Intermediate Care Units: The Italian Thoracic Society (ITS-AIPO) Position Paper}

\author{
Teresa Renda ${ }^{a}$ Raffaele Scala ${ }^{b}$ Antonio Corrado ${ }^{c}$ Nicolino Ambrosino ${ }^{d}$ \\ Adriano Vaghi ${ }^{e}$ on behalf of the Scientific Group on Respiratory Intensive \\ Care of the Italian Thoracic Society (ITS-AIPO) \\ ${ }^{a}$ Cardio-Thoracic and Vascular Department, Respiratory and Critical Care Unit, Careggi University Hospital, \\ Florence, Italy; ${ }^{b}$ Cardio-Neuro-Thoracic and Metabolic Department, Pulmonology and Respiratory Intensive Care

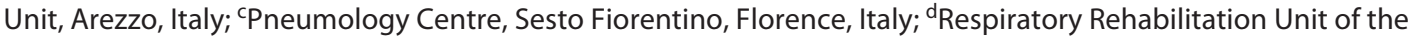

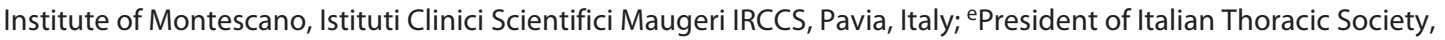 \\ Italian Association of Hospital Pulmonologists (ITS-AIPO), Milan, Italy
}

\section{Keywords}

Respiratory care units · Pulmonologist - Intensive care units - Acute respiratory failure $\cdot$ Cost-effectiveness

\begin{abstract}
The imbalance between the prevalence of patients with acute respiratory failure (ARF) and acute-on-chronic respiratory failure and the number of intensive care unit (ICU) beds requires new solutions. The increasing use of non-invasive respiratory tools to support patients at earlier stages of ARF and the increased expertise of non-ICU clinicians in other types of supportive care have led to the development of adult pulmonary intensive care units (PICUs) and pulmonary intermediate care units (PIMCUs). As in other European countries, Italian PICUs and PIMCUs provide an intermediate level of care as the setting designed for managing ARF patients without severe non-pulmonary dysfunction. The PICUs and PIMCUs may also act as step-down units for weaning patients from prolonged mechanical ventilation and for discharging patients still requiring ventilatory support at
\end{abstract}

karger@karger.com

(c) 2021 S. Karger AG, Basel

www.karger.com/res

Karger" home. These units may play an important role in the on-going coronavirus disease 2019 pandemic. This position paper promoted by the Italian Thoracic Society (ITS-AIPO) describes the models, facilities, staff, equipment, and operating methods of PICUs and PIMCUs.

(c) 2021 S. Karger AG, Basel

\section{Introduction}

Acute respiratory failure (ARF) represents one of the most important causes of intensive care unit (ICU) admission and readmission [1-3]. The limited availability of ICU beds represents a global problem, worsened during the current global outbreak of the severe acute respiratory syndrome coronavirus-2 (SARS-CoV-2) [4].

Even though with considerable geographic variability, a recent study [5] has shown that the mean availability of ICU beds in Europe is 11.5/100,000 inhabitants; this ratio is far lower than that reported in the USA, which is $34.0 / 100,000$ inhabitants [6]. In Italy, due to a reduced al- 
location of healthcare resources [7], the number of critical care beds dropped from 12.5 in 2011 [5] to 7.8/100,000 inhabitants in 2017 [8]. Between 2010 and 2017, there was a $16 \%$ reduction in the number of beds in Pulmonology Units [8]. Consistently, the imbalance between the increasing prevalence of critical patients with ARF and the shortage of high daily cost ICU beds has stimulated new health cost-effective solutions.

Pulmonary intensive care units (PICUs) and pulmonary intermediate care units (PIMCUs) provide a specialized environment for the management of patients with severe ARF requiring an "intermediate" level of care between the ICU and the ward, to avoid the dangerous "underassistance" in the latter and the unnecessary "overassistance" in the former. This is helpful to keep a larger number of ICU beds free for sicker patients needing multiple organ support. Their activity may include preferentially but not exclusively non-invasive ventilation (NIV) treatment of ARF, weaning patients from invasive ventilation, tracheostomy care, and decannulation and discharge planning for ventilator-dependent patients [9-11]. The complexity of the interventions performed in PICUs and PIMCUs has increased significantly over the last 15 years, moving from widespread use of NIV to the application of ultrafiltration methods, extracorporeal carbon dioxide removal $\left(\mathrm{ECCO}_{2} \mathrm{R}\right)$, high-flow oxygen therapy (HFOT), and analgosedation interventional procedures [12-17].

Two national surveys promoted by the Italian Thoracic Society (ITS) have shown a steady increase in the number of these units in Italy $[18,19]$. Unfortunately, the last ITS census of all respiratory units reports that the number of beds for critically ill respiratory patients is underrepresented as compared to the estimated requirement (0.8 vs. $1-2 / 100,000$ inhabitants) [10, 20]; moreover, PICU and PIMCU beds were found to be distributed heterogeneously across the country $[19,20]$.

The recent coronavirus disease 2019 (COVID-19) outbreak has demonstrated that the quick saturation of ICU beds with intubated patients could have been largely prevented if a stronger pulmonology network had been set up earlier to manage severe hypoxaemic patients with non-invasive respiratory techniques [21, 22]. Surprisingly, despite the strong rationale for the development of PICUs and PIMCUs, there are few recommendations and limited information about intermediate care facilities; moreover, these units are referred to in the literature under different names, such as "intermediate care units," "highly dependent units," "step-down units," and "semiintensive care units," and this has created confusion in the identification of their role in healthcare systems.

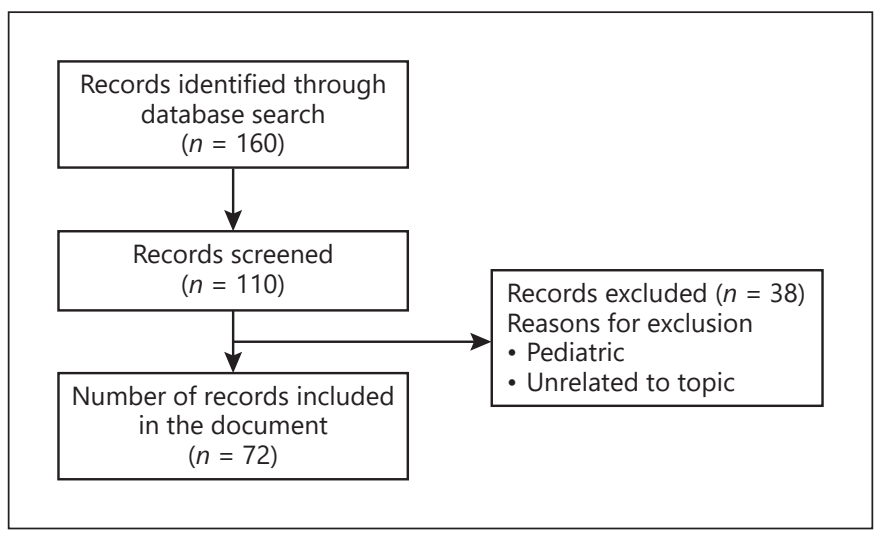

Fig. 1. Consort flow diagram of the review process. The diagram illustrates the flow of identified records leading to the final inclusion of publications reported in the manuscript.

This position paper represents an update of previous recommendations of the Italian Thoracic Society (ITSAIPO) and provides the minimum organizational standards for planning adult PICUs and PIMCUs $[10,11,23]$. The purpose of these recommendations is to promote better management of ARF and use of the resources available in health care.

\section{Methods}

Composition of the Study Group and Preparation of the Manuscript

The panel members (T.R., R.S., and A.C.) were selected by the ITS for their interest and expertise in respiratory critical care medicine. The expert panel was provided with background articles that reviewed the existing European and Italian documents on this topic [9-11] and the relevant articles obtained from a literature search. The panel produced a preliminary document, which was then subjected to external review (N.A.) for the final agreement. Consensus on the final document was achieved through a video conference, dealing with the following issues: (1) definition and level of care, (2) severity of respiratory failure, (3) economic and human resources, and (4) experienced staff and training.

The literature search was conducted through the PubMed National Library, Embase, and Google Scholar Beta databases, using the following keywords: "acute respiratory failure, ICU, respiratory care units, levels of care, Pulmonologist, mechanical ventilation, non-invasive ventilation, and cost-effectiveness" and specific keywords for each chapter of the document. Only publications in Italian and English were considered. Content experts were asked to indicate and add any studies, and a total of 160 articles were acquired. Those considered most appropriate and relevant for the update of the document were selected (Fig. 1).

Definitions and Levels of Care

The definition of PICUs and PIMCUs was expanded in view of the broader spectrum of related diseases and the recent techno- 
Table 1. Definition of the levels of care and proposed classification of PICUs and PIMCUs

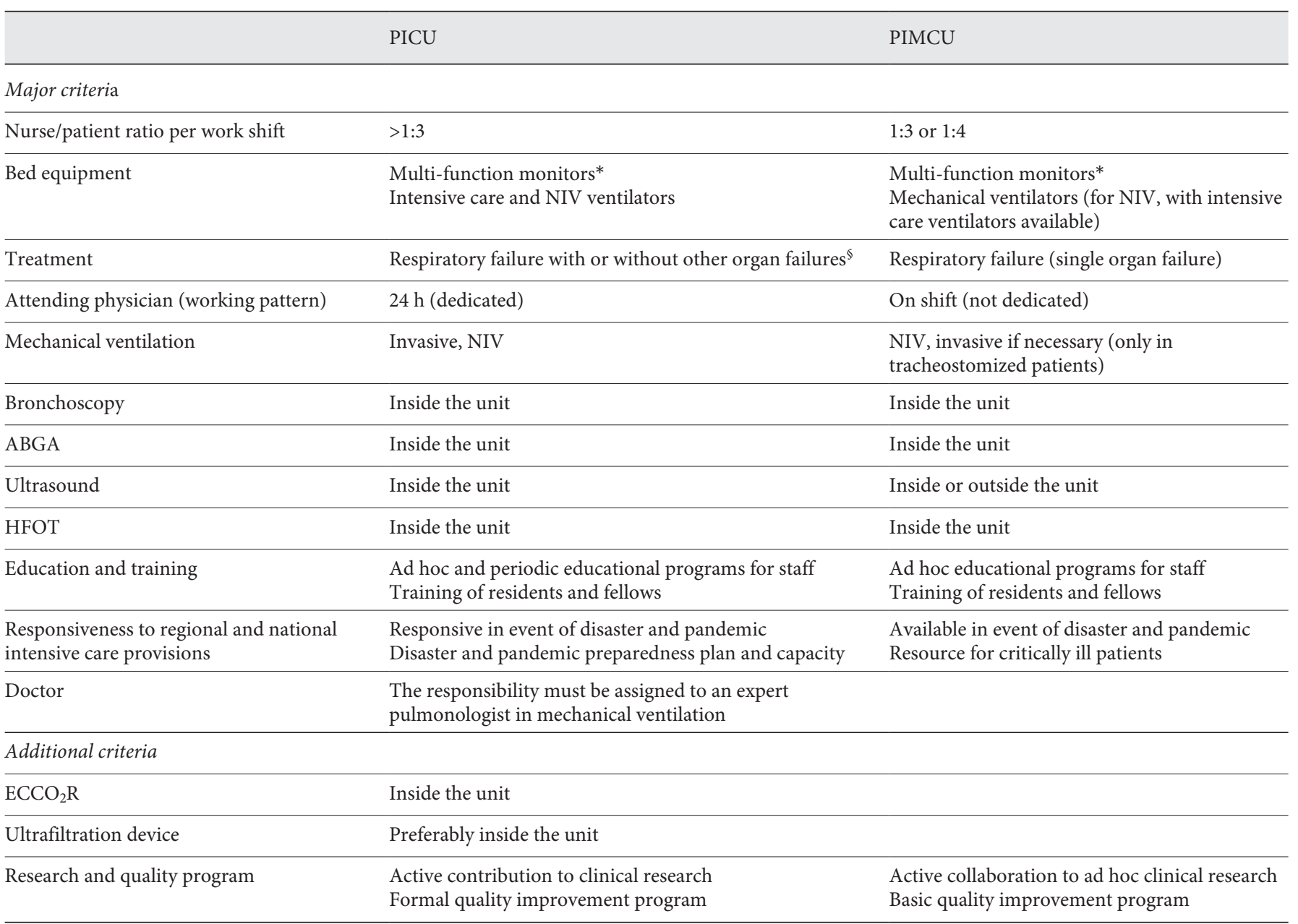

Although the criteria listed may vary depending on regional resources, capabilities, and various changeable clinical needs, all the main criteria must be satisfied to define a unit at each level. PICU, pulmonary intensive care unit; PIMCU, pulmonary intermediate care unit; NIV, non-invasive ventilation; EC$\mathrm{CO}_{2} \mathrm{R}$, extracorporeal $\mathrm{CO}_{2}$ removal; ABGA, arterial blood gas analyser; HFOT, high-flow oxygen therapy. * Multi-function monitors: oximetry, electrocardiogram, non-invasive blood pressure, and respiratory rate. ${ }^{\S}$ See Table 3 for clinical conditions requiring treatment in a general ICU.

logical enhancements of non-ventilatory support for critically ill respiratory patients $[9,11]$. The PICUs and PIMCUs are defined as "a pulmonary monitoring and treatment area for patients with acute respiratory failure and with acute-on-chronic respiratory failure in whom non-invasive monitoring and respiratory support (NRS) (e.g., NIV and HFOT) techniques are mainly used. Difficult to wean tracheostomized patients are also admitted from general ICUs. The discharge planning of ventilator-dependent patients is part of the activities. Interventional procedures, such as bronchoscopy and pleural drainage, chest ultrasound, and analgosedation, are usually performed in these units to facilitate the management of ventilated patients." An ERS Task Force and ITS documents identified 3 different levels of care among PICUs and PIMCUs (respiratory intensive care unit, respiratory intermediate care unit, and respiratory monitoring unit [MU]), stratified according to human and instrumental resources as well as the intensity of care $[9$, 11]. The authors approved the revised document, which main- tained the 2 higher levels of care: PICUs and PIMCUs $[9,11]$, but not MU.

The former definition of MU did not fit the revised PICU and PIMCU criteria for several reasons: (1) this setting is much more similar to a ward than to an intermediate care unit in terms of intensity and complexity of intervention; for example, NIV and HFOT may be safely provided also in a respiratory ward to treat selected patients with less severe ARF by an expert team [24-26]; (2) the term is misleading as the activity of PICUs and PIMCUs is not limited to a simple "monitoring" activity but provides "active" respiratory support; and (3) currently, in Italy, there are 2 levels of care for critically ill patients defined as intensive and intermediate care units according to the types and complexity of the interventions available. For these reasons, the panel agreed to consider 2 levels of units based on (1) the nurse/patient ratio, (2) interventions performed to update the instruments, and (3) admission criteria (Table 1). 
Table 2. Patients requiring treatment in adult PICUs and PIMCUs

COPD with ARF requiring mechanical ventilation, mainly non-invasive, and/or monitoring of vital parameters for ARF

Chronic restrictive diseases (neuromuscular and chest wall diseases and diffuse infiltrative lung disease) with ARF requiring mechanical ventilation, mainly non-invasive, and/or monitoring of vital parameters

Patients with central hypoventilation or sleep apnoea syndrome requiring hospitalization for ARF

Patients undergoing mechanical ventilation in an ICU, to complete weaning from the ventilator and/or to restore functional recovery before discharge to the hospital ward or home

Weaned tracheostomized patients to attempt decannulation

Patients requiring mechanical ventilation, mainly non-invasive, and/or monitoring of vital parameters due to respiratory complications after surgery

Patients requiring mechanical ventilation and/or monitoring of vital parameters for hypoxaemic ARF following pulmonary parenchyma diseases, with $\mathrm{PaO} 2 / \mathrm{FiO} 2$ ratio $<300$ and $>100$

Patients requiring mechanical ventilation and/or monitoring of vital parameters for acute asthma exacerbation

Patients needing interventional procedures (e.g., bronchoscopy, digestive endoscopy, PEG positioning, and trans-oesophageal echocardiography) with ARF during conventional oxygen therapy, HFOT, or NIV

PICU, pulmonary intensive care unit; PIMCU, pulmonary intermediate care unit; ARF, acute respiratory failure; COPD, chronic obstructive pulmonary disease; HFOT, high-flow oxygen therapy; NIV, non-invasive ventilation; $\mathrm{PaO}_{2} / \mathrm{FiO}_{2}$, partial oxygen pressure/fraction of inspired $\mathrm{O}_{2} ; \mathrm{PEG}$, percutaneous endoscopic gastrostomy.

Table 3. Clinical conditions requiring treatment in an ICU

Severe hypoxaemic ARF (severe ARDS) with $\mathrm{PaO}_{2} / \mathrm{FiO}_{2}$ ratio $<100$ during invasive ventilation applicable in rescue treatments such as ECMO, nitric oxide, and pronation

ARF with multiple organ dysfunction syndrome requiring multiple organ support

ARF in patients with severe cardiac haemodynamic/electrical instability, for example, uncontrolled cardiac arrhythmia and/or systolic hypotension $<70 \mathrm{~mm} \mathrm{Hg}$ despite volaemic filling and/or use of vasoactive amines

Septic shock with ARF (only for PICUs not equipped to perform haemodynamic monitoring)

ARDS, acute respiratory distress syndrome; ARF, acute respiratory failure; ECMO, extracorporeal membrane oxygenation; ICU, intensive care unit; PICUs, pulmonary intensive care units.

The first level corresponding to the PIMCU was characterized by a nurse/patient ratio of at least 1:4, the routine use of non-invasive monitoring, NRS, and the application of invasive mechanical ventilation when necessary. The second level corresponding to the PICU was characterized by a nurse/patient ratio $>1: 3$, with the possibility of managing ARF of any level of severity with invasive ventilation and NIV but not ARF with multiple organ failure requiring multiple organ support, cardiogenic shock requiring aortic counterpulsation, and severe refractory hypoxaemia requiring extracorporeal membrane oxygenation treatment. These conditions necessarily require treatment in general ICUs. Additional criteria were introduced regarding renal ultrafiltration and interventional lung assist for $\mathrm{ECCO}_{2} \mathrm{R}$. In recent years, reports from some PICUs have shown their capability to support patients presenting with both $\mathrm{ARF}$ and acute renal failure by means of ventilation and renal support (i.e., haemofiltration or dialysis) with the backup of intensivists and nephrologists. Finally, some centres have successfully applied $\mathrm{ECCO}_{2} \mathrm{R}$ to reduce the risk of NIV failure in severe chronic obstructive pulmonary disease (COPD) exacerbations and other chronic lung diseases $[13,15,27]$.

\section{Admission Criteria}

Admission to PICUs and PIMCUs depends on the following factors: (1) the level of intensity of care provided by the facility; (2) the task of the unit carried out in the clinical governance of ARF in the setting of the hospital or healthcare facility in which it is located (step-up from general wards and emergency medicine, stepdown from general ICUs, and weaning centre); and (3) the team's 


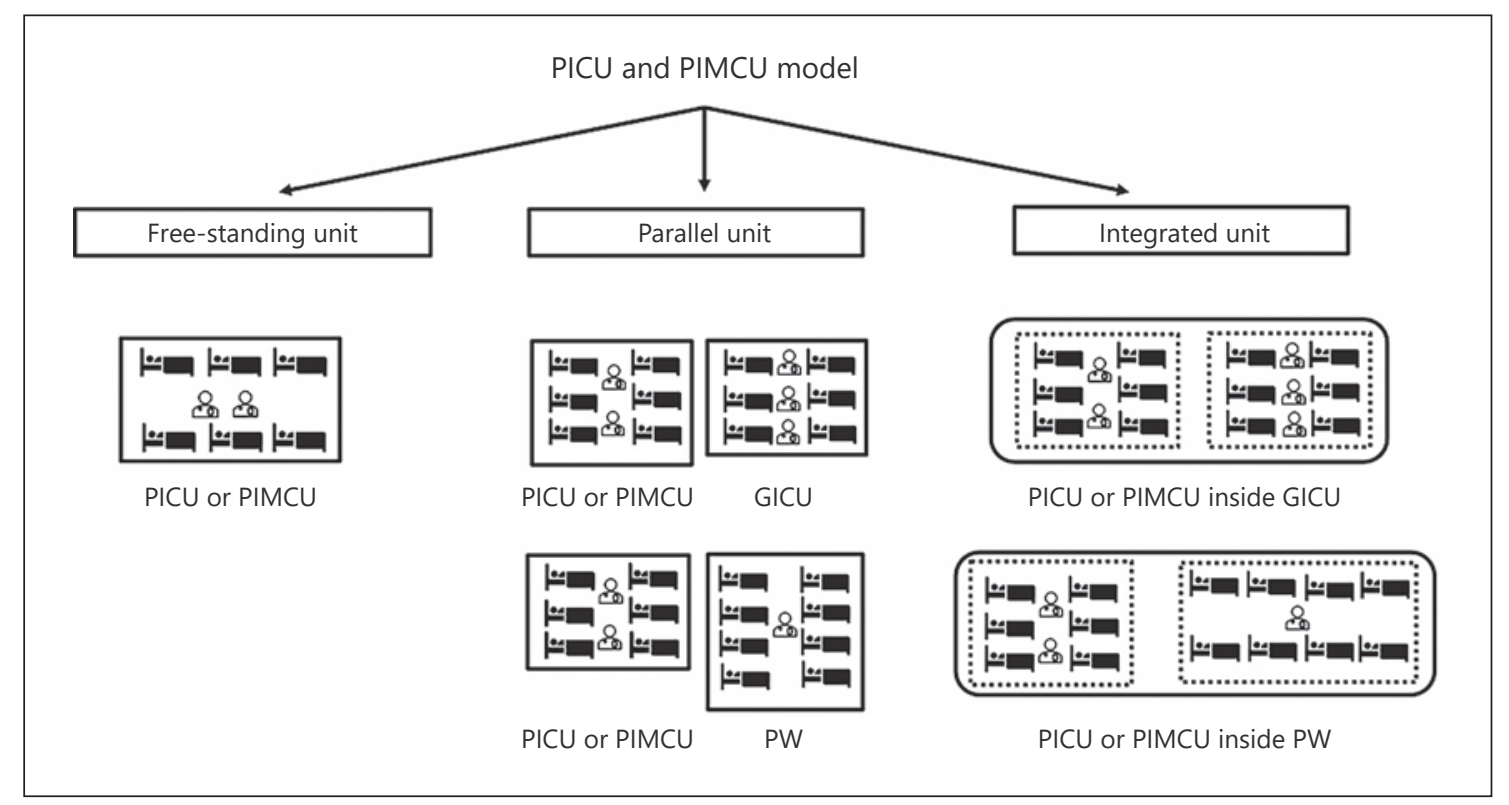

Fig. 2. Schematic representation of PICU and PIMCU location and model. Rectangles represent units with beds and nursing staff (nurse/patient ratio per work shift). GICU, general ICU; PICU, pulmonary intensive care unit; PIMCU, pulmonary intermediate care unit; PW, pulmonology ward.

experience in dealing with increasing levels of complexity of respiratory failure with NIV and invasive ventilation techniques.

Currently, there are no definitive guidelines on admission criteria to PICUs and PIMCUs; the admission criteria should be closely linked to the definition of the level of care and clinical management background of ARF [28] (Tables 2, 3). Moreover, each admission should be assessed on an individual basis, taking into account underlying disease severity and the patient's wishes or advance directives regarding life-support therapy.

\section{Discharge Criteria}

Direct discharge from a critical care setting into the community represents a controversial transition for patients [29]. The decision-making regarding readiness for discharge is complex; as soon as the patient's clinical conditions are stable, the treatment process should be transferred to units with a lower intensity care (general wards) or prolonged weaning centres, where they can receive functional assessments and rehabilitation before returning to the community.

The criteria suggested for discharge from PICUs and PIMCUs are as follows:

- Stable physiological status without any need for continuous cardiorespiratory monitoring.

- No fever.

- Complete or partial weaning from invasive mechanical ventilation with a stable respiratory status.

- Stable haemodynamic conditions (absence of uncontrolled arrhythmias, heart failure, or need for intravenous inotropic therapy).

- Stable pulmonary gas exchanges for at least $24 \mathrm{~h}$.

Once the patient meets the discharge criteria, in agreement with the patient and/or the caregivers, the appropriate time for transferring the patient to a ward or another structure (rehabilitation facilities, weaning centre, long-term ward, or protected residences) will have to be planned according to the clinical conditions, care needs, and social requirements. A direct transfer from a PICU to home should be reserved for specific cases where the patient and/or caregivers are strongly motivated and adequate care and support is available at home.

For tracheostomized patients, when possible, decannulation should be performed before discharge. Patients with ARF failing multiple attempts at weaning from mechanical ventilation ("chronic ventilator-dependent patients") require long-term ventilation.

In the case of discharged tracheostomized patients requiring periodic aspiration and/or mechanical ventilation at home, the patient and caregivers should have been given appropriate training, which must be demonstrated by a written report of the training activities actually carried out in the PICUs and PIMCUs. Last but not least, these units play a pivotal role in telemonitoring programs for ventilator-dependent patients [30].

\section{Organizational Model}

There are no guidelines or standards on the best location and design of PICUs and PIMCUs within the hospital [9]. Local considerations, including demand, ICU and ward case-mix, ICU volume, available staffing, and physical and financial resources, represent the key factors for the allocation of the PICUs and PIMCUs in real practice. Several models for the location of these units in a hospital have been proposed: independent location (free-standing unit), parallel model (adjacent to the ICU or colocated), and integrated model (within the ICU or in a Pulmonology Unit, functionally and ideally integrated with a sleep disorder laboratory) [3134] (Fig. 2).
Adult Pulmonary Intensive and Intermediate Care Units
Respiration 2021;100:1027-1037

DOI: $10.1159 / 000516332$ 
Locating PICUs or PIMCUs in a Pulmonology Unit and Sleep Disorder laboratory facilitates the integration of respiratory support, the monitoring of breathing resources, and the availability of an experienced team for both acute conditions and chronically ill patients needing titration of home mechanical ventilation (invasive ventilation and NIV). The integrated model in a Pulmonology Unit, adjusting treatment to the patient's needs in the same area, may ensure optimum continuity of treatment; furthermore, the costs of basic equipment per bed and personnel management (nurse to patient ratio) are lower than the integration model in an ICU.

There is no definitive scientific evidence on the recommended number of beds or size of PICUs and PIMCUs. These units should be based on a model of 4-8 beds in the Thoracic or Cardiothoracic Department or elsewhere, depending on the organizational level of the various local situations.

The optimal number of beds reported is as follows: (a) 4-6 for hospitals with $>500$ beds, (b) 8 beds for hospitals with $>1,000$ beds, or (c) 1-2 beds per 100,000 inhabitants [10]. The architectural and logistical characteristics of the PICUs and PIMCUs are listed in the online suppl. material (for all online suppl. material, see www. karger.com/doi/10.1159/000516332).

\section{Professionals and Training}

Professionals

The teams working in the PICUs and PIMCUs should include professional figures with a variety of skills. The personnel should consist of doctors, such as pulmonologists experienced in respiratory intensive care and airway management, and non-medical staff, such as nurses and respiratory physiotherapists; furthermore, the support of a clinical reference pharmacist is also desirable [35, 36]. In Italy, the minimum mandatory staff (clinicians, nurses, physiotherapists, and social healthcare operators [SHOs]) for the various levels of care is defined by regional and internal hospital regulations.

\section{Professional Nurses}

Adequate nurse staffing improves the quality of care and outcome of critically ill patients [37]. However, the optimal nurse to patient ratio in an ICU has not been fully established; this ratio is generally reported as 1:1 or 1:2.

In PICUs, the nurse/patient ratio per work shift must be $>1: 3$ calculated according to a bed/nursing unit/time per shift longer than 480 min [10]. In PIMCUs, the nurse/patient ratio per work shift must be 1:3 or 1:4 calculated according to a bed/nursing unit/ time per shift ranging from 360 to $480 \mathrm{~min}$ [10]. It is important for nurses to have specific knowledge and skills in critical care, NIRS, airway management, analgosedation, interventional procedures, and monitoring [38].

\section{Respiratory Physiotherapists}

The optimal physiotherapist to patient ratio should be 1:6 per work shift dedicated in the unit. Ideally, physiotherapists with dedicated training and expertise in critically ill patients should be available on a 7-day/week and 12-h/day shift basis [39-44].

Qualified Social Healthcare Operator

$\mathrm{SHOs}$ represent professional auxiliary figures. There is no evidence for providing recommendations on the specific $\mathrm{SHO} / \mathrm{pa}$ tient ratio. They carry out support tasks for nursing care, such as the delivery of biological materials for laboratory examinations, sterilization of clinical instruments, management of the material warehouse, and patient mobilization.

\section{Medical Staff}

The task force of the Society of Critical Care Medicine (SCCM) reports that there are currently no data available for providing recommendations on the specific intensivist/patient ratio $[45,46]$. However, it has been reported that a large number of patients per intensivist (1:15) is associated with a negative impact on patient care, especially in terms of days of hospitalization in intensive care [47].

In Italy, the workforce of medical staff in healthcare facilities lies within the responsibility of the regions, which, in turn, leaves the regulation of the internal organization to the individual healthcare facilities. PICUs require the presence of at least one exclusively dedicated doctor $24 \mathrm{~h}$ a day for a module of beds ranging usually from 4 to 8 [9-11]. In PIMCUs, the doctor must be immediately available in the ward $24 \mathrm{~h}$ a day, but he/she may also be responsible for ordinary hospital beds in the Pulmonology Unit (Table 1) $[9,11]$. The medical staff of PICUs and PIMCUs must be made up of pulmonologists experienced in respiratory intensive care, also familiar with airway and cardiopulmonary emergency management, mechanical ventilation, interventional procedures (i.e., bronchoscopy and pleural drainage), analgosedation, and all those other activities that the ERS HERMES (Harmonising Education in Respiratory Medicine for European Specialists) project specifically identifies [48].

\section{Staff Training}

There is a growing need for doctors and nurses with acute care skills to manage ARF patients, as demonstrated by the recent global health crisis due to the COVID-19 pandemic [49]. In Italy, unlike the situation in North America and UK, pulmonologists have not been involved with formal recognition in critical care medicine $[50,51]$. However, there are some specific requirements that more closely concern the activity of the pulmonologist working in the PICUs and PIMCUs for ensuring correct and safe management of critically ill patients, and these include the main cardiopulmonary resuscitation manoeuvres and airway management. The knowledge and skills of pulmonologists dealing with respiratory critical care and working in PICUs and PIMCUs [48] are divided between necessary and desirable [11], as reported in Table 4.

Furthermore, for the various operators (doctors, nurses, physiotherapists, and SHOs) working in the PICUs and PIMCUs, in addition to technical knowledge and skills, it would be desirable to implement internal training courses and the management of critical issues through training programmes and local simulation to improve and acquire the so-called "non-technical skills," such as communication between the various team members, leadership roles, the correct use of available resources, and the allocation of tasks $[49,52]$.

\section{Staff Organizational Requirements}

Advance team-based care is essential to improve ICU performance and teamwork. In addition to staff expertise, some specific aspects and skills including availability of appropriate equipment, quality of leadership, and organizational culture are essential to promote safety [52-56]. 
Table 4. Knowledge and skills required of the pulmonologist

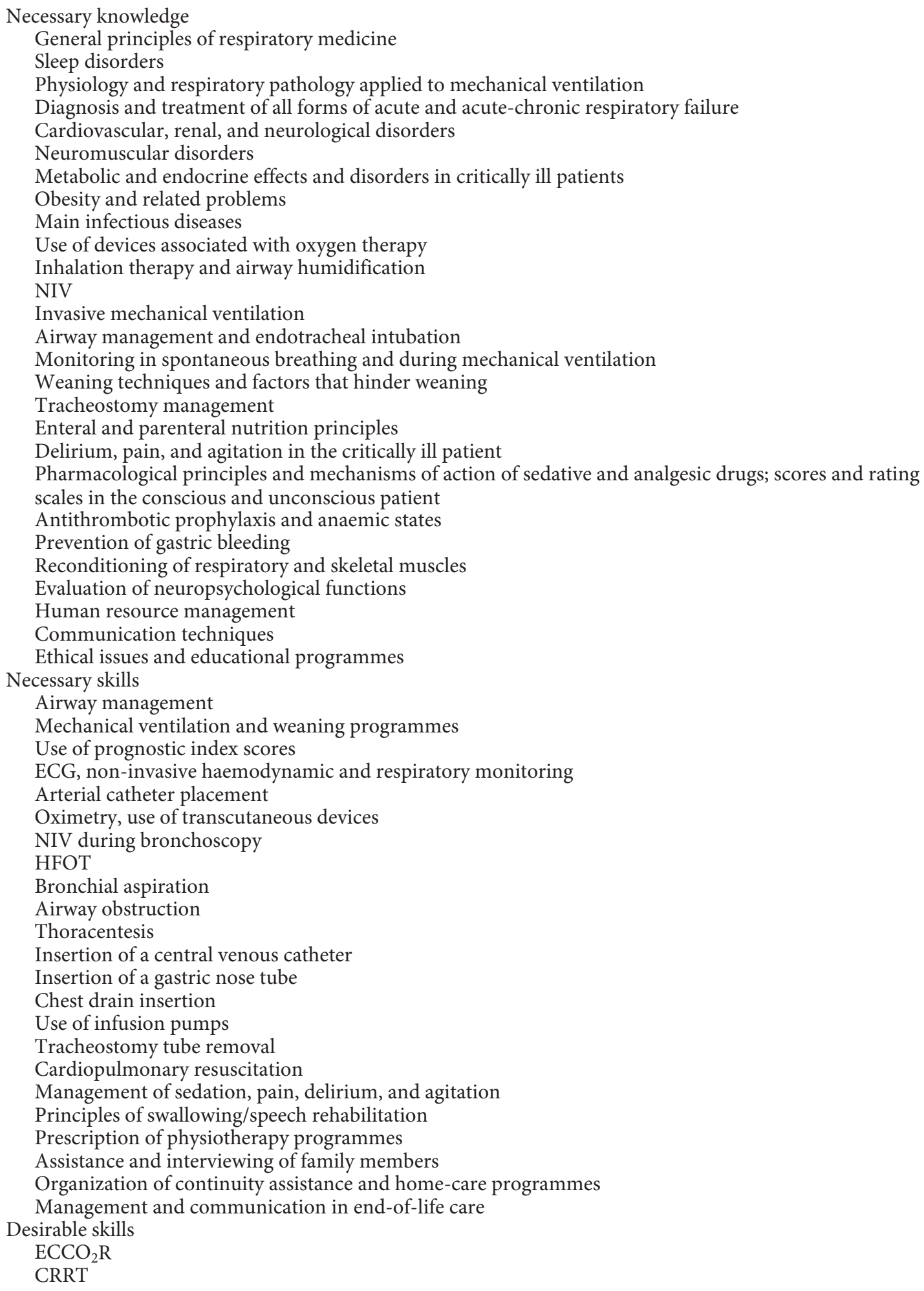

NIV, non-invasive ventilation; $\mathrm{ECCO}_{2} \mathrm{R}$, extracorporeal $\mathrm{CO}_{2}$ removal; HFOT, high-flow oxygen therapy; CRRT, continuous renal replacement therapy. 
PICUs and PIMCUs must comply with various organizational requirements:

1. The organizational chart of medical and nursing staff must be correlated with the type and volume of the activity performed and the interventions carried out by the unit.

2. There must be internal regulations and guidelines for carrying out the main activities in agreement with the professional organizational structures concerned, including the protocols for accessing the ward itself.

3. The organization of the work must include procedures for providing adequate responses to both routine requests and emergencies urgencies and the ability to scale up services in response to a natural disaster or pandemic outbreak.

4. Specific procedures to be followed in case of malfunctioning of the medical devices and gases must be provided.

5. Staff meetings should be systematically planned in order to discuss difficult cases and ethical decision-making, to provide training needs, share protocols, and organization of the unit.

Moreover, infection is an important aspect to take into account in the organization of PICUs and PIMCUs. All patients "should be in virtual isolation"; single rooms (with both negative and positive pressure as needed) are strongly recommended to minimize cross contamination [44, 49, 54, 57-59]. A detailed list of design and technical requirements for PICUs and PIMCUs is provided in the online supplementary material.

\section{Economic Aspects and Outcome}

Economic Aspects

It has been shown that about $40 \%$ of the patients admitted to ICUs never receive active intensive care, including mechanical ventilation, and therefore may be considered ideal candidates for specialized intermediate respiratory care units [9]. It is difficult to calculate the management costs of PICUs and PIMCUs due to the scarce availability of tools for evaluating the workloads of the personnel employed in the various operational settings. An important aspect of the activity is the scarce remuneration of hospitalization based on the DRG (diagnosis-related group) system and the concomitant limitation of resources allocated [60-63]. The current application of the DRG system for the evaluation of the healthcare activity carried out in PICUs and PIMCUs greatly underestimates the consumption of the resources employed compared to the healthcare requirements of the cases treated. Even though the costs for the management of acute-on-chronic respiratory failure are lower in a PIMCU than in a general ICU [64], the DRG system penalizes the reimbursement for NIV, due to a lack of formal recognition of the "weight" of NIV [62] and other new techniques, such as HFOT and ECCO2R, in the coding of the interventions performed for the treatment of ARF and acute-on-chronic respiratory failure.

The potential improvement in efficiency associated with the availability of PICU/PIMCUs and the simultaneous reduction in the medical nursing staff/patient ratio have been emphasized as elements capable of determining a reduction in the cost management of patients with ARF. Indeed, studies on in-depth economic analysis are still extremely scarce, and their conclusions are conflicting $[65,66]$. However, it has been reported that admission to a PIMCU of patients with severe exacerbated COPD gives outcomes similar to those obtained in the general ICU but with lower management costs attributable mainly to the setting, ventilation therapy, and non-invasive cardiorespiratory monitoring [64].

\section{Outcome}

Although there are theoretical assumptions to support the improvement of the outcome of patients with ARF following the introduction of PIMCUs, the studies published on this topic are relatively scarce, in most cases retrospective and at times contradictory [67-69]. It has recently been reported that the opening of a PIMCU in a general hospital is associated with an improvement in the prognosis of patients with ARF, exacerbation of COPD, or community-acquired pneumonia in terms of a reduction of inhospital mortality, the need for admission to the general ICU, and the length of the hospital stay [70].

These results can be explained by the appropriate and timely use of NIV, made possible by the presence of an expert and dedicated personnel as well as the availability of monitoring resources, dedicated respiratory physiotherapists, and a concentration of specialist cases. Nevertheless, taking into account the somewhat contradictory results of the reported studies, the lack of shared criteria for admission to the general ICUs and PICUs/PIMCUs, and the risk of a further increase in hospital spending, some intensivistanaesthesiologists have proposed the placing of intensive and intermediate therapy beds in the same area as the most efficient organizational solution. This could allow for the concentration of expensive equipment, as well as greater flexibility in the use of the beds and the medical nursing staff [71]. A recent Italian study has shown that using NRS is feasible and associated with favourable outcomes in patients with severe $\mathrm{ARF}\left(\mathrm{PaO}_{2} / \mathrm{FiO}_{2} 152 \pm 79\right)$ due to SARS-CoV-2 infection treated in newly developed dedicated COVID respiratory monitoring and respiratory intermediate care units with experienced staff [22].

The COVID-19 pandemic has led to huge sustained demand for critical care beds. In late February 2020, the Italian government delivered a directive to regional health authorities to increase their ICU capacity by $50 \%$ and to double the number of "pneumonia beds" within a few weeks. More than 10,000 patients had been treated and discharged from Italian Pulmonology wards. Of these patients, 42 were treated with NIV (82\% in full pandemic) and $17 \%$ with invasive mechanical ventilation [72]. The PICUs/PIMCUs have played a strategic role in linking the activity of general ICUs with lower intensity wards. The general mortality of COVID-19 patients hospitalized in Italian Pulmonology wards was $12 \%$ in the first wave of the pandemic, and $22 \%$ of patients were transferred from a general ICU (step-down), while only $11 \%$ were transferred from PICUs/PIMCUs to a general ICU (step-up) [72].

\section{Conclusions}

This document provides an organizational framework and detailed recommendations for the planning of PICUs and PIMCUs that need to be adapted to local conditions and the ever-changing dynamics of health care. The number of critical care beds, trained staff, and technological resources has not been enough to meet the continuously growing demand both in Italy and worldwide as demonstrated in the recent pandemic. Intensive care units and intermediate care units have become necessary to provide optimal care and contain the SARS-CoV-2 pandemic 
with an unexpected modification at Italian hospitals in which pulmonologists have played a central role.

The purpose of this position paper is to promote better management of ARF and the resources available in health care. Further research on the use of PICUs/PIMCUs and its effects on hospital outcomes is however necessary.

\section{Acknowledgements}

We extend our gratitude to the other members of the Scientific Group on Respiratory Intensive Care of the ITS-AIPO, all pulmonologists, and health-care workers who have worked during the COVID-19 pandemic. We also thank AIPO Ricerche for their administrative and technical support.

\section{Statement of Ethics}

This paper did not require ethics approval.

\section{Conflict of Interest Statement}

T.R., R.S., N.A., and A.V. have no conflicts of interest to disclose. A.C. declares that he has financial relationships with Linde.

\section{Funding Sources}

There was no funding.

\section{Author Contributions}

Conception: T.R., R.S., and A.C. Drafting the work: T.R., R.S., A.C., and A.V. Critical review of the manuscript: N.A. All authors improved and approved the final version of the manuscript.

\section{Collaborators}

Scientific Group on Respiratory Intensive Care of the ITS-AIPO: Arcaro G., Baglioni S., Brunetti G., Carlucci A., Carlucci B., Ceriana P., Clini E.M., Eslami A., Galavotti V., Marchese S., Mollica C., Perretta E., Pisani L., Starace A., Vagheggini G., Vianello A., and Vitacca M.

\section{References}

1 Bellani G, Laffey JG, Pham T, Fan E, Brochard L, Esteban A, et al. Epidemiology, patterns of care, and mortality for patients with acute respiratory distress syndrome in intensive care units in 50 countries. JAMA. $2016 \mathrm{Feb} ; 315(8)$ : 788-800.

2 van der Sluijs AF, van Slobbe-Bijlsma ER, Chick SE, Vroom MB, Dongelmans DA, Vlaar APJ. The impact of changes in intensive care organization on patient outcome and cost-effectiveness-a narrative review. J Intensive Care. 2017 Jan 25;5:13.

3 Lai CC, Tseng KL, Ho CH, Chiang SR, Chen $\mathrm{CM}$, Chan KS, et al. Prognosis of patients with acute respiratory failure and prolonged intensive care unit stay. J Thorac Dis. 2019;11(5): 2051-7.

4 Bauer J, Brüggmann D, Klingelhöfer D, Maier W, Schwettmann L, Weiss DJ, et al. Access to intensive care in 14 European countries: a spatial analysis of intensive care need and capacity in the light of COVID-19. Intensive Care Med. 2020 Nov;46(11):2026-34.

5 Rhodes A, Ferdinande P, Flaaten H, Guidet B, Metnitz PG, Moreno RP. The variability of critical care bed numbers in Europe. Intensive Care Med. 2012 Oct;38(10):1647-53.

6 Wallace DJ, Angus DC, Seymour CW, Barnato AE, Kahn JM. Critical care bed growth in the United States. A comparison of regional and national trends. Am J Respir Crit Care Med. 2015 Feb 15;191(4):410-6.

7 De Belvis AG, Ferrè F, Specchia ML, Valerio L, Fattore G, Ricciardi W. The financial crisis in Italy: implications for the healthcare sector. Health Policy. 2020 Jun;106(1):10-6.

8 Pecoraro F, Clemente F, Luzi D. The efficiency in the ordinary hospital bed management in Italy: an in-depth analysis of intensive care unit in the areas affected by COVID-19 before the outbreak. PLoS One. 2020 Sep 22;15(9): e0239249.

9 Corrado A, Roussos C, Ambrosino N, Confalonieri M, Cuvelier A, Elliott M, et al. Respiratory intermediate care units: a European survey. Eur Respir J. 2002 Nov;20(5):134350.

10 Corrado A, Ambrosino N, Cavalli A, Gorini M, Navalesi P, Confalonieri M, et al. Respiratory intensive care unit: an update. Rassegna di Patologia dell'Apparato Respiratorio. 2004 Feb;19(1):18-34.

11 Renda T, Arcaro G, Baglioni S, Brunetti G, Carlucci A, Carlucci B, et al. Respiratory intensive care unit: 2018 update. Rassegna di Patologia dell'Apparato Respiratorio. 2018 Dec;33(6):306-32.

12 Vianello A, Arcaro G, Braccioni F, Gallan F, Greggio CM, Marangoni A, et al. Management of tracheal intubation in the respiratory intensive care unit by pulmonary physicians. Respir Care. 2007 Jan;52(1):26-30.

13 Arcaro G, Vianello A. The successful management of a patient with exacerbation of noncystic fibrosis bronchiectasis and bilateral fibrothorax using a venovenous extracorporeal carbon dioxide removal system. Respir Care. 2014 Dec;59(12):e197-200.
14 Vianello A, Arcaro G, Paladini L, Iovino S Successful management of acute respiratory failure in an idiopathic pulmonary fibrosis patient using an extracorporeal carbon dioxide removal system. Sarcoidosis Vasc Diffuse Lung Dis. 2016 Aug;33(2):186-90.

15 Del Sorbo L, Pisani L, Filippini C, Fanelli V, Fasano L, Terragni P, et al. Extracorporeal carbon dioxide removal in hypercapnic patients at risk of noninvasive ventilation failure: a matched cohort study with historical control. Crit Care Med. 2015 Jan;43(1):1207.

16 Vega ML, Pisani L. Nasal high flow oxygen in acute respiratory failure. Pulmonology. 2021 May-Jun;27(3):240-7.

17 Vianello A, Arcaro G, Molena B, Turato C, Sukthi A, Guarnieri G, et al. High-flow nasal cannula oxygen therapy to treat patients with hypoxemic acute respiratory failure consequent to SARS-CoV-2 infection. Thorax. 2020 Nov;75(11):998-1000.

18 Confalonieri M, Gorini M, Ambrosino N, Mollica C, Corrado A. Scientific group on respiratory intensive care of the Italian association of hospital pneumonologists. Respiratory intensive care units in Italy: a national census and prospective cohort study. Thorax. 2001 May;56(5):373-8.

19 Scala R, Corrado A, Confalonieri M, Marchese S, Ambrosino N. Increased number and expertise of Italian respiratory high-dependency care units: the second national survey. Respir Care. 2011 Aug;56(8):1100-7. 
20 Nutini S, De Michele F, Corrado A. AIPO census for proper planning of Italian pneumology. Rassegna di Patologia dell'Apparato Respiratorio. 2014;29(6):311-7.

21 Scala R, Renda T, Corrado A, Vaghi A. Italian pulmonologist units and COVID-19 outbreak: "mind the gap"!. Crit Care. 2020 Jun; 24(1):381.

22 Franco C, Facciolongo N, Tonelli R, Dongilli R, Vianello A, Pisani L, et al. Feasibility and clinical impact of out-of-ICU noninvasive respiratory support in patients with COVID19-related pneumonia. Eur Respir J. 2020 Nov;56(5):2002130.

23 Corrado A, Ambrosino N, Rossi A, Donner CF. Gruppo di Studio AIPO "Riabilitazione e Terapia Intensiva Respiratoria”. Unità di terapia intensiva respiratoria. Rassegna di Patologia dell'Apparato Respiratorio. 1994;9:11523.

24 Plant PK, Owen JL, Elliott MW. Early use of non-invasive ventilation for acute exacerbations of chronic obstructive pulmonary disease on general respiratory wards: a multicentre randomised controlled trial. Lancet. 2000 Jun;355(9219):1931-5.

25 Dave C, Turner A, Thomas A, Beauchamp B, Chakraborty B, Ali A, et al. Utility of respiratory ward-based NIV in acidotic hypercapnic respiratory failure. Respirology. 2014 Nov; 19(8):1241-7.

26 Koyauchi T, Hasegawa H, Kanata K, Kakutani T, Amano Y, Ozawa Y, et al. Efficacy and tolerability of high-flow nasal cannula oxygen therapy for hypoxemic respiratory failure in patients with interstitial lung disease with donot-intubate orders: a retrospective singlecenter study. Respiration. 2018 Jun;96(4): 323-9.

27 Maggiorelli C, Ciarleglio G, Granese V, Maccari U, Manta C, Madioni C, et al. Integrated therapeutic strategy during noninvasive ventilation in a patient with end-stage respiratory disease. Respir Care. 2015 Apr;60(4):e80-5.

28 Scala R. Respiratory high-dependency care units for the burden of acute respiratory failure. Eur J Intern Med. 2012 Jun;23(4):302-8.

29 Basmaji J, Lau V, Lam J, Priestap F, Ball IM. Lessons learned and new directions regarding discharge direct from adult intensive care units sent home (DISH): a narrative review. J Intensive Care Soc. 2019 May;20(2):165-70.

30 Ambrosino N, Vitacca M, Dreher M, Isetta V, Montserrat JM, Tonia T, et al. Tele-monitoring of ventilator-dependent patients: a European respiratory society statement. Eur Respir J. 2016 Sep;48(3):648-63.

31 Ferrer M, Torres A. Intermediate respiratory care units. In: Vincent JL, editor. Intensive care medicine. yearbook of intensive care and emergency medicine 2007. Berlin: Springer Berlin Heidelberg; 2007. Vol. 41; p. 505-12.

32 Torres A, Ferrer M, Blanquer JB, Calle M, Casolivé V, Echave JM, et al. Intermediate respiratory intensive care working group of the spanish society of pulmonology and thoracic surgery (SEPAR). Intermediate respiratory intensive care units: definitions and characteristics. Arch Bronconeumol. 2005 Sep; 41(9):505-12.

33 Marchioni A, Tonelli R, Sdanganelli A, Gozzi F, Musarò L, Fantini R, et al. Prevalence and development of chronic critical illness in acute patients admitted to a respiratory intensive care setting. Pulmonology. 2020 MayJun;26(3):151-8.

34 Guia M, Ciobanu LD, Sreedharan JK, Abdelrahim ME, Gonçalves G, Cabrita B, et al. International association of non invasive ventilation. The role of non-invasive ventilation in weaning and decannulating critically ill patients with tracheostomy: a narrative review of the literature. Pulmonology. 2021 Jan-Feb; 27(1):43-51.

35 Rivkin A, Yin $\mathrm{H}$. Evaluation of the role of the critical care pharmacist in identifying and avoiding or minimizing significant drug-drug interactions in medical intensive care patients. J Crit Care. 2010 Jun;26(1):104-6.

36 Donovan AL, Aldrich JM, Gross AK, Barchas DM, Thornton KC, Schell-Chaple HM, et al. University of California, San Francisco critical care innovations groupinterprofessional care and teamwork in the ICU. Critical Care Medicine. 2018 Jun;46(6):980-90.

37 Sakr YS, Moreira CL, Rhodes A, Ferguson ND, Kleinpell R, Pickkers P, et al. The impact of hospital and ICU organizational factors on outcome in critically ill patients. Crit Care Med. 2015 Mar;43(3):519-26.

38 Sneyers B, Laterre PF, Perreault MM, Wouters D, Spinewine A. Current practices and barriers impairing physicians' and nurses' adherence to analgo-sedation recommendations in the intensive care unit-a national survey. Crit Care. 2014 Dec 5;18(6):655.

39 Connolly B, O'Neill B, Salisbury L, Blackwood B. Enhanced recovery after critical illness programme groupphysical rehabilitation interventions for adult patients during critical illness: an overview of systematic reviews. Thorax. 2016 Oct;71(10):881-90.

40 Gosselink R, Bott J, Johnson M, Dean E, Nava $S$, Norrenberg M, et al. Physiotherapy for adult patients with critical illness: recommendations of the European respiratory society and European society of intensive care medicine task force on physiotherapy for critically ill patients. Intensive Care Med. 2008 Jul;34(7):1188-99.

41 Hanekom S, Gosselink R, Dean E, van Aswegen H, Roos R, Ambrosino N, et al. The development of a clinical management algorithm for early physical activity and mobilization of critically ill patients: synthesis of evidence and expert opinion and its translation into practice. Clin Rehabil. 2011 Sep;25(9):771-87.

42 Wright SE, Thomas K, Watson G, Baker C, Bryant A, Chadwick TJ, et al. Intensive versus standard physical rehabilitation therapy in the critically ill (EPICC): a multicentre, parallel-group, randomised controlled trial. Thorax. 2018 Mar;73(3):213-21.

43 Vitacca M, Carone M, Clini EM, Paneroni M, Lazzeri M, Lanza A, et al. ITS/AIPO, the ARIR and the SIP/IRS. Joint statement on the role of respiratory rehabilitation in the COVID-19 crisis: the Italian position paper. Respiration. 2020 May;99(6):493-9.

44 Valentin A, Ferdinande P; ESICM Working Group on Quality Improvement. Recommendations on basic requirements for intensive care units: structural and organizational aspects. Intensive Care Med. 2011 Oct;37(10): 1575-87.

45 Ward NS, Afessa B, Kleinpell R, Tisherman S, Ries M, Howell M, et al. Members of society of critical care medicine taskforce on ICU staffing. Intensivist/patient ratios in closed ICUs: a statement from the society of critical care medicine taskforce on ICU staffing. Crit Care Med. 2013 Feb;41(2):638-45.

46 Ward NS, Howell MD. Intensivist-to-patient ratios in ICUs: is there a number? Curr Opin Anaesthesiol. 2015 Apr;28(2):172-9.

47 Dara SI, Afessa B. Intensivist-to-bed ratio: association with outcomes in the medical ICU. Chest. 2005 Aug;128(2):567-72.

48 Artigas A, Pelosi P, Dellweg D, Brochard L, Ferrer M, Geiseler J, et al. ERS educational task force on respiratory critical care HERMES. Respiratory critical care HERMES syllabus: defining competencies for respiratory doctors. Eur Respir J. 2012 Jun;39(6): 1294-7.

49 Phua J, Weng L, Ling L, Egi M, Lim CM, Divatia JV, et al. Asian critical care clinical trials group. Intensive care management of coronavirus disease 2019 (COVID-19): challenges and recommendations. Lancet Respir Med. 2020 May;8(5):506-17.

50 Evans T, Elliot MW, Ranieri M, Seeger W, Similowski T, Torres A, et al. Pulmonary medicine and (adult) critical care medicine in Europe. Eur Respir J. 2002 Jun;19(6):1202-6.

51 Facciolongo N, Scala R, Garuti G, Confalonieri $\mathrm{M}$, Corrado A. National survey on training and clinical practice of the pneumologist in respiratory intensive care. Rassegna di Patologia dell'Apparato Respiratorio. 2010;25(1): $36-43$.

52 Reader T, Flin R, Lauche K, Cuthbertson BH. Non-technical skills in the intensive care unit. Br J Anaesth. 2006 May;96(5):551-9.

53 Sprung CL, Zimmerman JL, Christian MD, Joynt GM, Hick JL, Taylor B, et al. Recommendations for intensive care unit and hospital preparations for an influenza epidemic or mass disaster: summary report of the European society of intensive care medicine's task force for intensive care unit triage during an influenza epidemic or mass disaster. Intensive Care Med. 2010 Mar;36(3):428-43.

54 Ervin JN, Kahn JM, Cohen TR, Weingart LR. Teamwork in the intensive care unit. Am Psychol. 2018 May-Jun;73(4):468-77.

55 Ippolito M, Vitale F, Accurso G, Iozzo P, Gregoretti C, Giarratano A, et al. Medical masks and respirators for the protection of healthcare workers from SARS-CoV-2 and other viruses. Pulmonology. 2020 Jul-Aug; 26(4):204-12. 
56 Winck JC, Ambrosino N. COVID-19 pandemic and non invasive respiratory management: every goliath needs a david. An evidence based evaluation of problems. Pulmonology. 2020 Jul-Aug;26(4):213-20.

57 Thompson DR, Hamilton DK, Cadenhead CD, Swoboda SM, Schwindel SM, Anderson DC, et al. Guidelines for intensive care unit design. Crit Care Med. 2012 May;40(5):1586600.

58 Saran S, Gurjar M, Baronia A, Sivapurapu V, Ghosh PS, Raju GM, et al. Heating, ventilation and air conditioning (HVAC) in intensive care unit. Crit Care. 2020 May;24(1):194.

59 Alhazzani W, Møller MH, Arabi YM, Loeb M, Gong MN, Fan E, et al. Surviving sepsis campaign: guidelines on the management of critically ill adults with coronavirus disease 2019 (COVID-19). Intensive Care Med. 2020 May; 46(5):854-87.

60 Potena A, Ballerin L, Putinati S, Piattella M, Cellini M, Buniolo C, et al. Quality of generated diagnosis related groups in Italian respiratory intermediate care units. Monaldi Arch Chest Dis. 2004 Jan-Mar;61(1):14-8.

61 Klein-Hitpaß U, Scheller-Kreinsen D. Policy trends and reforms in the German DRGbased hospital payment system. Health Policy. 2015 Mar;119(3):252-7.
62 Geissler A, Quentin W, Busse R. Heterogeneity of European DRG systems and potentials for a common EuroDRG system Comment on "cholecystectomy and diagnosis-related groups (DRGs): patient classification and hospital reimbursement in 11 European countries”. Int J Health Policy Manag. 2015 Mar 5;4(5):319-20.

63 Mayoralas-Alises S, Díaz-Lobato S, Granados-Ulecia C. Non-invasive ventilation: has it been forgotten in the diagnosis-related groups? Arch Bronconeumol. 2016 May; 52(5):281-2.

64 Bertolini G, Confalonieri M, Rossi C, Rossi G, Simini B, Gorini M, et al. Costs of the COPD. Differences between intensive care unit and respiratory intermediate care unit. Respir Med. 2005 Jul;99:894-900.

65 Byrick RJ, Mazer CD, Caskennette GM. Closure of an intermediate care unit. Impact on critical care utilization. Chest. 1993 Sep; 104(3):876-81.

66 Solberg BC, Dirksen CD, Nieman FH, van Merode G, Poeze M, Ramsay G. Changes in hospital costs after introducing an intermediate care unit: a comparative observational study. Crit Care. 2008 May;12(3):R68.

67 Barnato AE, Albert SM, Angus DC, Lave JR. Disability among elderly survivors of mechanical ventilation. Am J Respir Crit Care Med. 2011 Apr;183(8):1037-42.
68 Calvo-Ayala E, Khan BA, Farber MO, Ely EW, Boustani MA. Interventions to improve the physical function of ICU survivors: a systematic review. Chest. 2013Nov;144(5):146980.

69 Morris PE, Griffin L, Berry M, Thompson C, Hite RD, Winkelman C, et al. Receiving early mobility during an intensive care unit admission is a predictor of improved outcomes in acute respiratory failure. Am J Med Sci. 2011 May;341(5):373-7.

70 Confalonieri M, Trevisan R, Demsar M, Lattuada L, Longo C, Cifaldi R, et al. Opening of a respiratory intermediate care unit in a general hospital: impact on mortality and other outcomes. Respiration. 2015 Jul;90(3):23542.

71 Vincent JL, Rubenfeld GD. Does intermediate care improve patient outcomes or reduce costs? Crit Care. 2015 Mar; 19(1):89.

72 Vaghi A. Le risposte della Pneumologia alla sfida sanitaria della pandemia da COVID19 - Analisi Questionario III AIPO-ITS Available from: http://www.aiponet.it/news/ speciale-COVID-19/2510-l-impegno-deglipneumologi-italiani-nella-sfida-della-pandemia-da-COVID-19.html 